\title{
Further insight into the mechanism of hydrocarbon layer formation below the divertor of ASDEX Upgrade
}

\author{
M. Mayer, V. Rohde, and ASDEX Upgrade Team \\ Max-Planck-Institut für Plasmaphysik, EURATOM Association, Boltzmannstr. 2, \\ D-85748 Garching, Germany \\ E-mail: Matej .Mayer@ipp.mpg.de
}

\begin{abstract}
The surface loss probability of hydrocarbon radicals was measured below the roof baffle of the ASDEX Upgrade divertor using the cavity technique. Hydrocarbon layers are mainly formed by sticking of hydrocarbon radicals with high surface loss probabilities of about 0.2 and close to unity. In addition to sticking re-erosion by atomic hydrogen plays an important role in layer formation. The temperature dependence of layer formation was measured with heated and cooled long term samples from $77 \mathrm{~K}$ to $475 \mathrm{~K}$. The layer growth rate is larger by a factor of about 40 at $77 \mathrm{~K}$ compared to room temperature, while it is lower by a factor of about 70 at $475 \mathrm{~K}$ than at room temperature due to enhanced re-erosion. Implications of the results for predictions of tritium retention in future fusion devices and hydrocarbon layer formation on mirror surfaces are discussed.
\end{abstract}

PACS numbers: 52.40.Hf; 52.55.Fa; 28.52.Fa; 52.55.Rk; 82.80.Yc

\section{Introduction}

Major disadvantage of carbon as first wall material is its propensity to trap large amounts of hydrogen by codeposition with eroded carbon atoms [1], which may result in unacceptably high tritium inventories in ITER [2, 3, 4]. Hydrogen rich amorphous hydrocarbon layers (a-C:D layers) were observed on the tiles in the inner divertors of JET [5, 6] and ASDEX Upgrade [7]. But hydrocarbon layers are also observed in areas without direct plasma contact, such as the louvers in the JET Mark IIA and Mark IIGB divertors [5, 8], or the area below the divertor IIb of ASDEX Upgrade [8, 9, 10, 11]. These remote areas are only accessible for neutral particles, because they can be reached only by traversing the toroidal magnetic field. It was shown in low-temperature plasma experiments, that neutral hydrocarbon radicals such as $\mathrm{CH}_{3}, \mathrm{C}_{2} \mathrm{H}_{x}$ (with $x=1,3,5$ ), and heavier hydrocarbon molecules, can contribute significantly to the growth of a-C:D layers [12], and it was assumed that hydrocarbon radicals are also responsible for the formation of codeposited layers in fusion devices [12, 13, 14].

Future devices like ITER will use in-vessel mirrors for several diagnostics [15]. Some mirrors are foreseen to be used in the divertor region. As long as carbon is used inside 
the machine, there is concern that a-C:D layers will be deposited on mirror surfaces, resulting in a change of the optical reflectivity of the mirrors [15]. This may require frequent calibration of the corresponding diagnostic. Methods preventing the deposition of a-C:D layers on mirror surfaces are highly desirable.

Reactive species hitting a wall may adsorb with a sticking probability $s$, can react to a non-reactive molecule (for example $\mathrm{CD}_{3}$ to $\mathrm{CD}_{4}$ ) with probability $\gamma$, or may be reflected with probability $r$ [12]. The surface loss probability $\beta$ is given by $\beta=s+\gamma$, with $r+s+\gamma=1$. There is some indication from ASDEX Upgrade, that at least two different species contribute to layer growth [11]: A low sticking species with $\beta<10^{-3}$ is responsible for layer formation at very remote areas such as pump ducts, while a species with higher sticking probability $(0.1 \leq \beta \leq 0.9)$ results in a position dependent layer deposition with maximum thicknesses in line-of-sight to the strike points and with decreasing thickness to more distant regions. At JET, three different species with $\beta \approx 1$, $\beta=0.9$ and $\beta=10^{-3}$ were observed [8].

In this paper we present new measurements on the surface loss probabilities of hydrocarbon radicals in ASDEX Upgrade. Moreover, we will show that not only sticking of hydrocarbon radicals, but in addition re-erosion of already deposited layers by lowenergetic atomic hydrogen is an important mechanism for layer formation, especially at elevated temperatures.

\section{Experimental}

\subsection{Cavity samples}

Four cavity samples were exposed below the roof baffle of the ASDEX Upgrade divertor during the discharge campaign 2002/2003 from 11/2002 to 08/2003. During this time 1237 discharges with 4944 s plasma in divertor configuration were performed.

Locations of the cavity samples are shown in Figure 1 together with a schematic representation of the samples. The cavities consist of $0.41 \mathrm{~mm}$ thick silicon top and bottom plates with a $0.8 \mathrm{~mm}$ wide entrance slit. Hydrocarbon radicals enter the cavity through the slit and can either stick to the bottom plate of the cavity, or they can be reflected if their reflection probability $r>0$. The radical now can stick to the top plate, or it can be reflected again until it finally sticks, is converted to a stable volatile molecule, or it leaves the cavity through the slit. A typical deposition profile, as obtained from a Monte-Carlo computer simulation, is shown in Figure 1. The detailed shape of the material distribution on the bottom and top plates is determined by the reflection coefficient $r$.

Cavity C 3 was exposed in the inner divertor. Cavities C 1 and $\mathrm{C} 4$ were placed in the outer divertor, with $\mathrm{C} 1$ looking towards the outer strike point and $\mathrm{C} 4$ oriented parallel to the magnetic field. C 2 was exposed in the outer divertor pump duct entrance. 


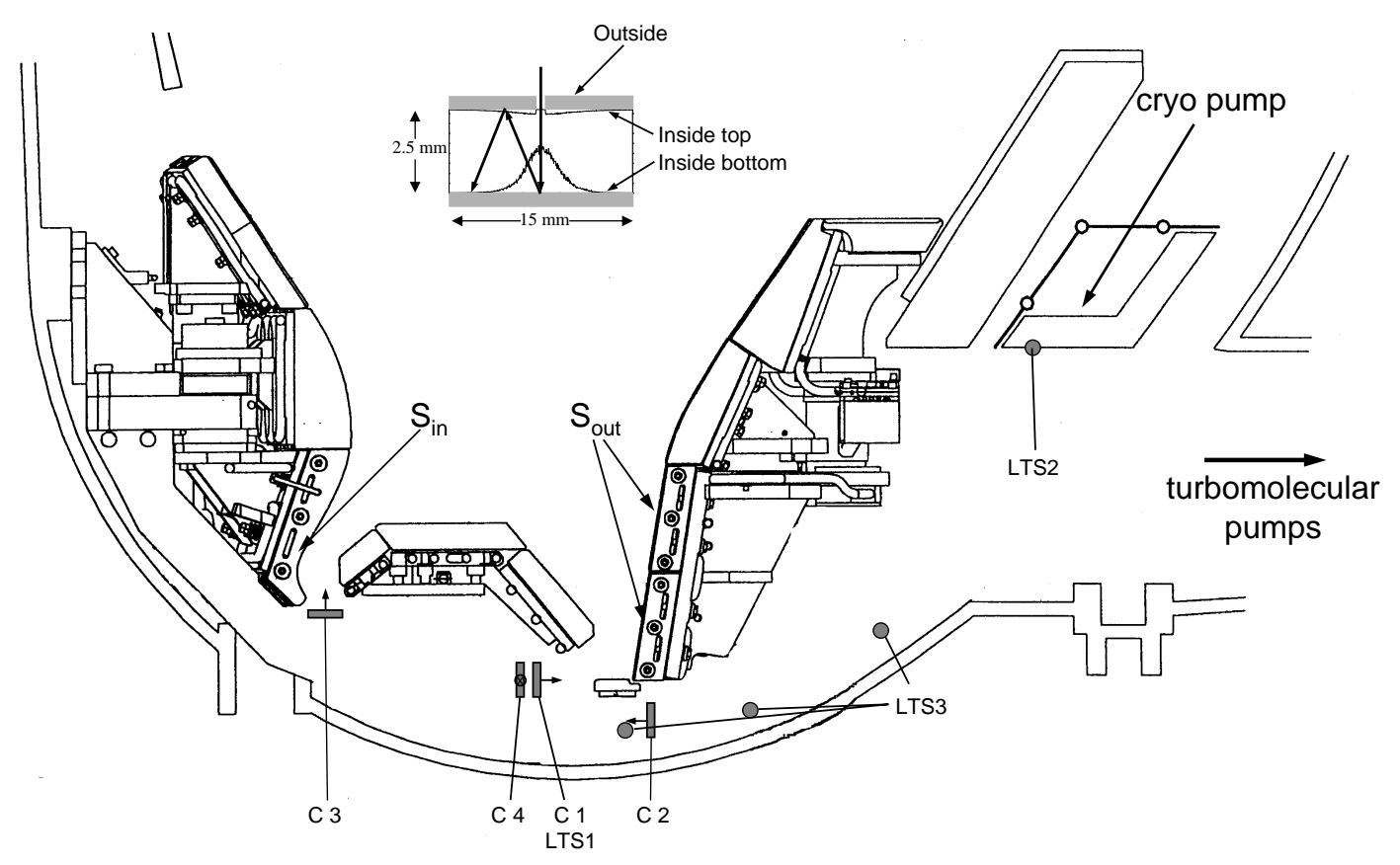

Figure 1. Cavity samples (C1-C4) and long term samples (LTS1-LTS3) in the divertor of ASDEX Upgrade. Arrows show the orientation of the cavity entrance slit. C 4 was oriented into the paper plane, parallel to the magnetic field. $S_{i n}$ : Inner strike point tile; $S_{\text {out }}$ : Outer strike point tiles. Inset: Schematic representation of a cavity sample together with a Monte-Carlo simulation of a deposition pattern inside the cavity (not to scale).

\subsection{Long term samples on the panels of the divertor cryo pump}

Two long term samples (LTS2, see Figure 1) were exposed on the panels of the divertor cryo pump during the discharge campaign 2002/2003 from 11/2002 to 08/2003. The samples were about $65 \mathrm{~cm}$ away from the outer divertor strike point. Sample temperatures were $77 \mathrm{~K}$ during most of the campaign. The samples were only heated to room temperature during week-ends and boronizations. Three additional LTS (LTS3 in Figure 1) were placed in the pump duct between the divertor and the cryo pump at distances between 25 and $55 \mathrm{~cm}$ from the strike point. These samples were at room temperature.

\subsection{Heated long term samples}

Three heated long term samples were exposed below the roof baffle of the ASDEX Upgrade divertor during the discharge campaign 2003/2004 from 11/2003 to 08/2004. During this time 1302 discharges with 3940 s plasma in divertor configuration were performed. The samples (LTS1, see Figure 1) were facing the outer divertor tiles 
at a comparable position to cavity $\mathrm{C} 1$, see Figure 1 . The sample radiators were manufactured by SINTEC and had dimensions of $10 \times 10 \mathrm{~mm}^{2}$. They consist of a boron-nitride $(\mathrm{BN})$ heater element with an electrically isolated graphite heating coil having an electrical resistance of about $6 \Omega$. The radiators were heated by constant electric current during the whole discharge period except during vessel openings. The heating current was regularly monitored. The samples consisted of small pieces of Si wafers with dimensions $3 \times 8 \mathrm{~mm}^{2}$. Sample temperatures were not measured in situ due to lack of in-vessel cabling, but sample temperatures were calibrated as a function of heating current in a laboratory device in vacuum using an infrared camera. Sample temperatures during plasma discharges can be somewhat above the nominal temperatures due to additional radiation heating from the plasma. Three additional long term samples at room temperature were placed between the heated samples.

\subsection{Ion beam analysis}

Deposited layers were quantitatively analyzed using ion beam analysis methods. Deuterium was detected using the $\mathrm{D}\left({ }^{3} \mathrm{He}, \mathrm{p}\right) \alpha$ nuclear reaction at $800 \mathrm{keV}$ and $2500 \mathrm{keV}$ incident energies [16]. Carbon and boron were detected using the ${ }^{12} \mathrm{C}\left({ }^{3} \mathrm{He}, \mathrm{p}\right){ }^{14} \mathrm{~N}$ and ${ }^{11} \mathrm{~B}\left({ }^{3} \mathrm{He}, \mathrm{p}\right){ }^{13} \mathrm{C}$ nuclear reactions at $2500 \mathrm{keV}$ incident energy. The beam spot size was $0.3 \times 1 \mathrm{~mm}^{2}$. The protons were detected using a large angle proton counter having a solid angle of $0.14 \mathrm{sr}$. The counter was covered with a $10 \mu \mathrm{m} \mathrm{Ni}$ foil in order to stop backscattered ${ }^{3} \mathrm{He}$ ions. Heavier elements were measured using Rutherford backscattering at $165^{\circ}$ with $2500 \mathrm{keV}{ }^{3} \mathrm{He}$ ions. The spectra were analyzed using the SIMNRA program [17, 18].

\section{Computer simulation}

Computer simulations of deposition patterns inside the cavities were made according to the model described in full detail in [12].

- Particles enter the cavity through the entrance slit with a $\cos ^{n}$ distribution, where $n$ is adjusted for best fit.

- At each surface the particles may either stick with probability $s$, they may be reflected with probability $r$, or they may react to a stable molecule (for example $\mathrm{CD}_{3}$ to $\mathrm{CD}_{4}$ ) with probability $\gamma$. The surface loss probability $\beta$ is given by $\beta=s+\gamma$, with $\beta+r=1$. We used $\gamma=0$.

- Particles are reflected with a cosine distribution from all surfaces. The assumption of a cosine distribution gave best fit to laboratory experiments [12].

- The gas pressure inside the cavities is $<10^{-3}$ mbar, resulting in mean free path lengths $>8 \mathrm{~mm}$, which is larger than the dimensions of the cavities. Collisions with gas molecules are neglected. 
The deposition profile inside the cavities can be obtained from a Monte-Carlo (MC) simulation [11]. Major disadvantage of the MC approach is the long computing time. For simple geometries and without collisions with gas molecules a ray-tracing type approach [12] is faster. The calculation is performed in two dimensions. For two parallel plates the flux per unit area $\Phi_{2}$ at a point 2 on plate 2 originating from a point 1 on plate 1 is given by

$$
\Phi_{2} \sim r \cos \theta d_{12}^{-1} \Phi_{1}
$$

where $r$ is the reflection coefficient, $\theta$ the angle towards the surface normal, and $d_{12}$ the distance between the two points. $\Phi_{1}$ is the flux per unit area at point 1 . The flux

onto every surface inside the cavity after each reflection can be calculated by integrating over all surfaces and all possible angles. The film thickness distribution is calculated by consecutive reflections of the incoming flux $\Phi_{0}$. For each reflection the flux is reduced proportional to $r$ and due to the escape of particles through the slit. $N$ reflections are followed until the flux $\Phi_{N}$ drops to $\Phi_{N} / \Phi_{0}<10^{-3}$. The ray-tracing is done in two dimensions. The MC simulation code and the ray-tracing code were benchmarked against each other and gave similar results.

\section{Results}

\subsection{Cavity samples}

Deuterium and carbon distributions inside cavities $\mathrm{C} 1$ (outer divertor) and $\mathrm{C} 3$ (inner divertor) are shown in Figure 2 and Figure 3. A coverage of about $2 \times 10^{16}$ carbon atoms $/ \mathrm{cm}^{2}$ was observed on all surfaces, even below screw heads or other areas covered by metal enclosures. This carbon coverage was also detected at areas where deuterium was not observed. It therefore does not originate from plasma operation, but results from carbon or hydrocarbon contamination during sample storage or during analysis. The amount of $2 \times 10^{16}$ carbon atoms $/ \mathrm{cm}^{2}$ was subtracted from all data points shown in Figure 2 and Figure 3, resulting in large inaccuracies in the carbon determination in the corners of the cavities, where the carbon coverage is low. The boron coverage and amounts of heavier elements ( $\mathrm{such}$ as $\mathrm{Fe}, \mathrm{Ni}, \mathrm{Cu}, \mathrm{W}$ ) were below the detection limit of about $10^{14}$ atoms $/ \mathrm{cm}^{2}$. 


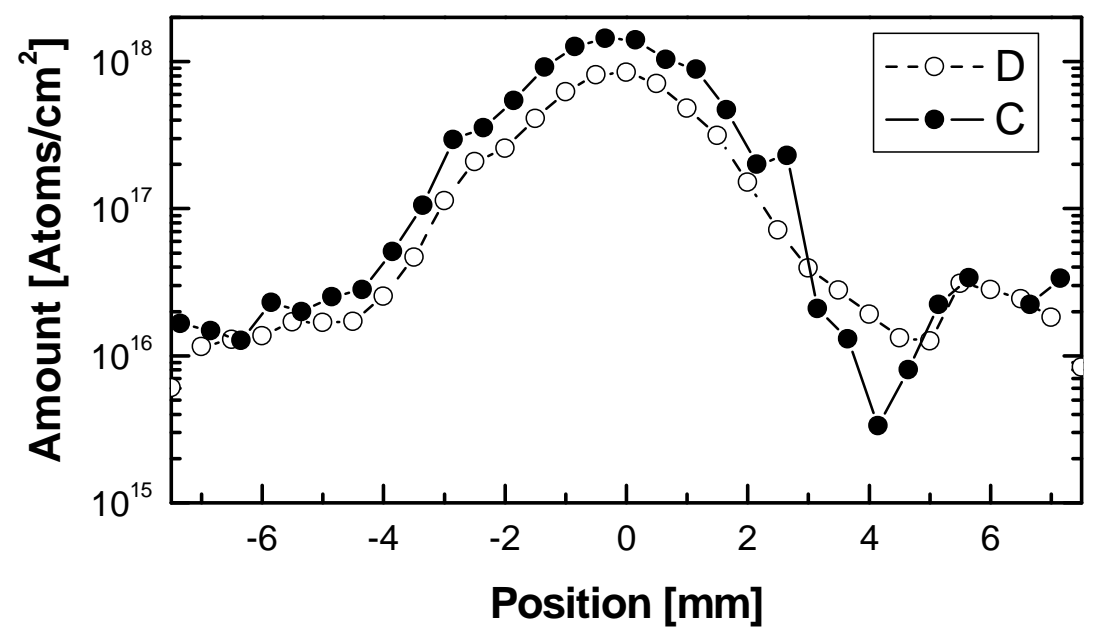

Figure 2. Distribution of $\mathrm{D}$ and $\mathrm{C}$ at the bottom plate of cavity $\mathrm{C} 1$ (outer divertor). The zero point on the horizontal axis is opposite the entrance slit. 


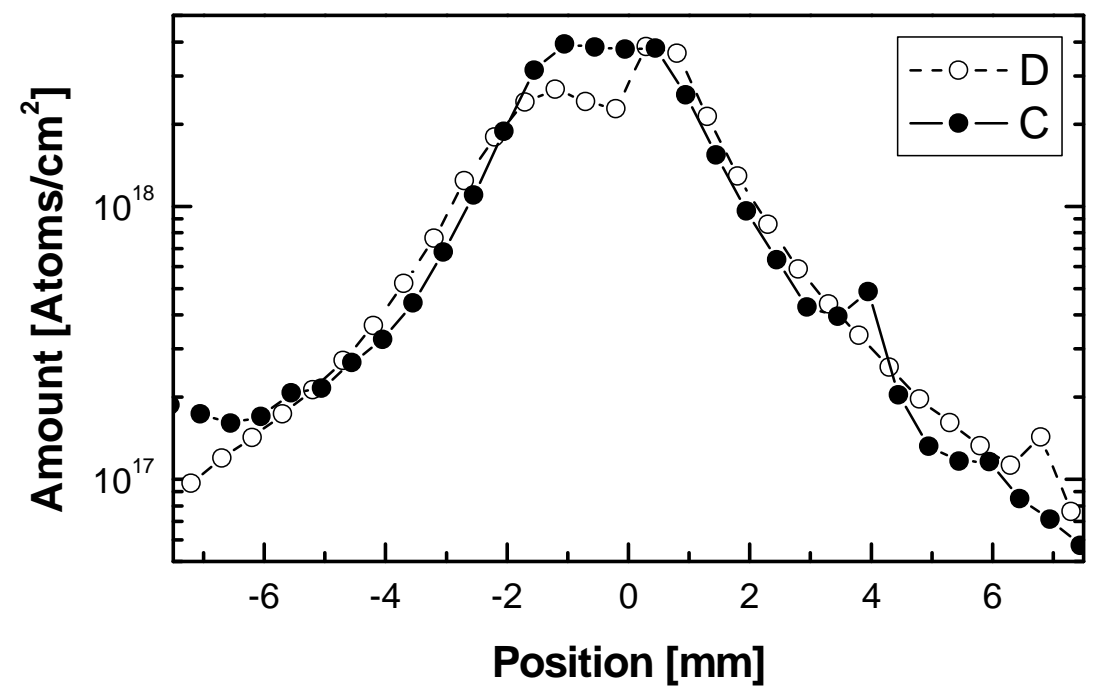

Figure 3. Distribution of $\mathrm{D}$ and $\mathrm{C}$ at the bottom plate of cavity $\mathrm{C} 3$ (inner divertor). The zero point on the horizontal axis is opposite the entrance slit.

Table 1. Some properties of the hydrocarbon layers in the cavities.

\begin{tabular}{llcccc} 
Cavity & Location & $\begin{array}{c}\text { Max. amount of } \mathrm{D} \\
\text { Bottom plate } \\
\text { atoms } / \mathrm{cm}^{2}\end{array}$ & $\begin{array}{c}\mathrm{D} / \mathrm{C} \text { ratio } \\
\text { Bottom plate }\end{array}$ & $\begin{array}{c}\text { Amount of D } \\
\text { Outside } \\
\text { atoms } / \mathrm{cm}^{2}\end{array}$ & $\begin{array}{c}\mathrm{D} / \mathrm{C} \text { ratio } \\
\text { Outside }\end{array}$ \\
\hline $\mathrm{C} 1$ & Outer divertor & $8.4 \times 10^{17}$ & $0.4-0.5$ & $9.6 \times 10^{17}$ & 0.53 \\
$\mathrm{C} 2$ & Outer divertor & $7.9 \times 10^{16}$ & - & $4.3 \times 10^{17}$ & 0.96 \\
$\mathrm{C} 3$ & Inner divertor & $3.8 \times 10^{18}$ & $0.5-1.0$ & $3.7 \times 10^{17}$ & 0.66 \\
$\mathrm{C} 4$ & Outer divertor & $1.1 \times 10^{17}$ & $0.4-0.5$ & $5.1 \times 10^{17}$ & 0.49 \\
\hline
\end{tabular}

Thicknesses and some properties of the layers at the inside bottom plates and on the outside faces (see the inset in Figure 1 for a definition of the different faces) are summarized in Table 1. Soft amorphous hydrocarbon layers with $\mathrm{D} / \mathrm{C}$ in the range 0.5-1 are observed, both inside the cavities and on the outside faces.

The maximum deposition on the bottom plate just opposite the entrance slit should be about six times smaller than on the outer side due to the smaller solid angle. As can be seen from Table 1, this ratio is approximately observed for C 2 and C 4 (5.4 and 4.6, respectively), but not for $\mathrm{C} 1$ and $\mathrm{C} 3$, where it is 1.1 and 0.1 . The deposition at the outer side of $\mathrm{C} 3$ is even ten times smaller than inside the cavity, although it should be 6 times larger: This unexpected result will be discussed in section 5 .

The deuterium distribution inside C 2 is shown in Figure 4. The entrance slit of the cavity was partly shadowed by the sub-divertor structure, resulting in an asymmetric deposition pattern. The deposition pattern can be explained by:

(i) The deposition just opposite the slit results mainly from particles with $\beta \approx 1$, i.e. from particles which stick at the first surface they hit. The deposition pattern 
reflects the distribution of carbon sources, and the cavity acts as a pinhole camera. The deposition pattern is strongly asymmetric due to shadowing of the entrance slit by the sub-divertor structure. This asymmetry was not taken into account in the simulation calculations shown in Figure 4. About $85 \%$ of the deposition in cavity C 2 originates from these particles.

(ii) The corners of the cavity and the top plates can be reached only after several wall collisions. The observed deposition pattern can be fitted with $0.1 \leq \beta \leq 0.3$. Best fit is obtained for $\beta=0.2$, which is shown in Figure 4 . About $15 \%$ of the deposition originates from these particles.

(iii) Particles with very low surface loss probabilities $\beta \ll 0.1$ result in a small and (almost) homogeneous deposition on all surfaces. The cavities used in our measurements are not sensitive to these particles, if higher sticking particles are also present. We cannot draw any conclusions about very low sticking particles from the current measurements with the cavity probes.

(iv) The deposition at the top plates just opposite of the entrance slit $(-2 \mathrm{~mm} \leq$ $x \leq 2 \mathrm{~mm}$ ) is not described by the model. This deposition is correlated with the deposition at the bottom plate and may originate from re-erosion of the deposited layer from the bottom plate, which is then re-deposited at the top plates with high sticking probability $s=1$. However, the distribution of ejected particles cannot be described by a cosine distribution, but is more strongly peaked towards the surface normal. Such enhanced deposition at the top plates in vicinity to the entrance slit was already observed in laboratory experiments [19, Fig. 5], but has not been explained up to now.

Cavity $\mathrm{C} 4$ showed very similar results as cavity $\mathrm{C} 2$ : the deposition pattern could be fitted with two species having $\beta \approx 1$ and $\beta=0.2 \pm 0.1$, where the high sticking species was responsible for about $89 \%$ of the deposition. A similar disagreement at the top plates just opposite the entrance slit as in cavity C 2 was observed.

The deuterium distribution inside cavity C 3 (inner divertor) together with computer simulations of the distribution is shown in Figure 5. The distribution at the bottom plate can be well described by two species, one with $\beta=0.7 \pm 0.1$ (about $67 \%$ of the deposition) and another with $\beta \approx 1$ (about $33 \%$ of the deposition). However, the amount of $\mathrm{D}$ on the inner top plates is too low by about two orders of magnitude, compared to the model. As was already pointed out above and can be seen in Table 1, the deposition at the outer side of this cavity was already too small by a factor of about 60. I.e. the deposition of $\mathrm{D}$ and $\mathrm{C}$ on the top plates of this cavity (both inside and outside) is too small by a factor of 50-100. This is due to re-erosion of the already deposited layers, and will be discussed in more detail in section 5 . Because re-erosion is not included in the computer simulation of the deposition pattern, the value of $\beta=0.7$ may suffer from large inaccuracies.

Cavity C 1 (outer divertor) showed comparable results as cavity C 3: the deposition pattern could be fitted with two species, having $\beta=0.3 \pm 0.2$ ( $13 \%$ of the deposition) 

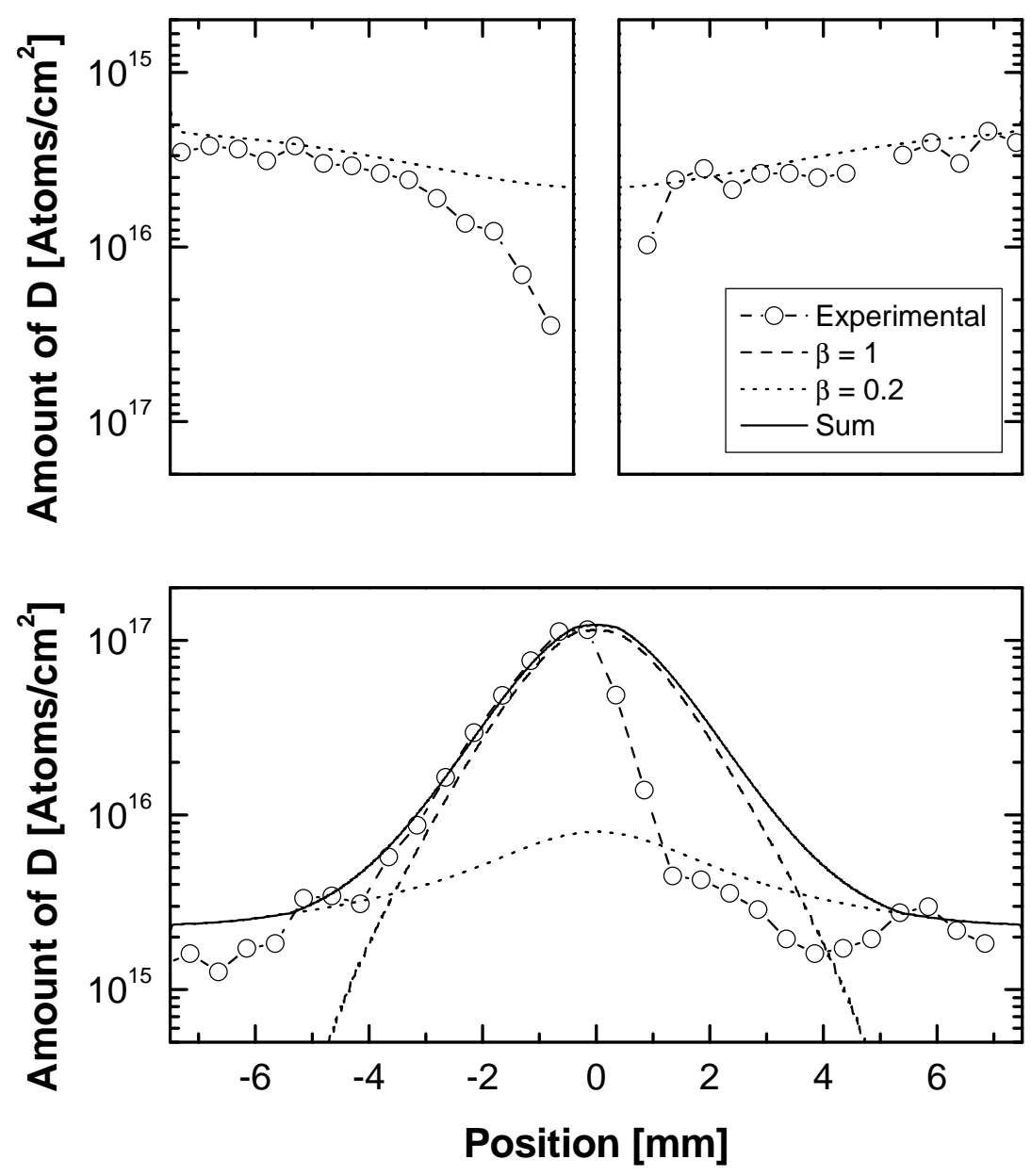

Figure 4. Deuterium distribution inside cavity C 2. Top: top plates; bottom: bottom plate. Note the inverted vertical scale for the deposit on the top plates reflecting their downward growth. Lines: Computer simulations of the deposition pattern using surface loss probabilities of $\beta=0.2, \beta=1.0$, and the sum of both. The area with $x \geq 0$ was shadowed behind a tile.

and $\beta \approx 1$ ( $87 \%$ of the deposition). The amount of $\mathrm{D}$ on the inner top plates was too low by a factor of 5-10, compared to the model. A similar disagreement was already observed between the deposition opposite the entrance slit inside, and outside of the cavity, see Table 1.

\subsection{Long term samples on cryo panels}

The deuterium deposition on the LTS in the pump duct was about $1 \times 10^{16} \mathrm{D}$-atoms $/ \mathrm{cm}^{2}$. The amount of deuterium on the $77 \mathrm{~K}$ cryo-panel samples was about $4 \times 10^{17} \mathrm{D}$ atoms $/ \mathrm{cm}^{2}$, i.e. about 40 times larger than at room temperature, although these samples were further away from the divertor strike point. The cold samples showed also a very high $\mathrm{D} / \mathrm{C}$ ratio of $1.3-1.7$. 

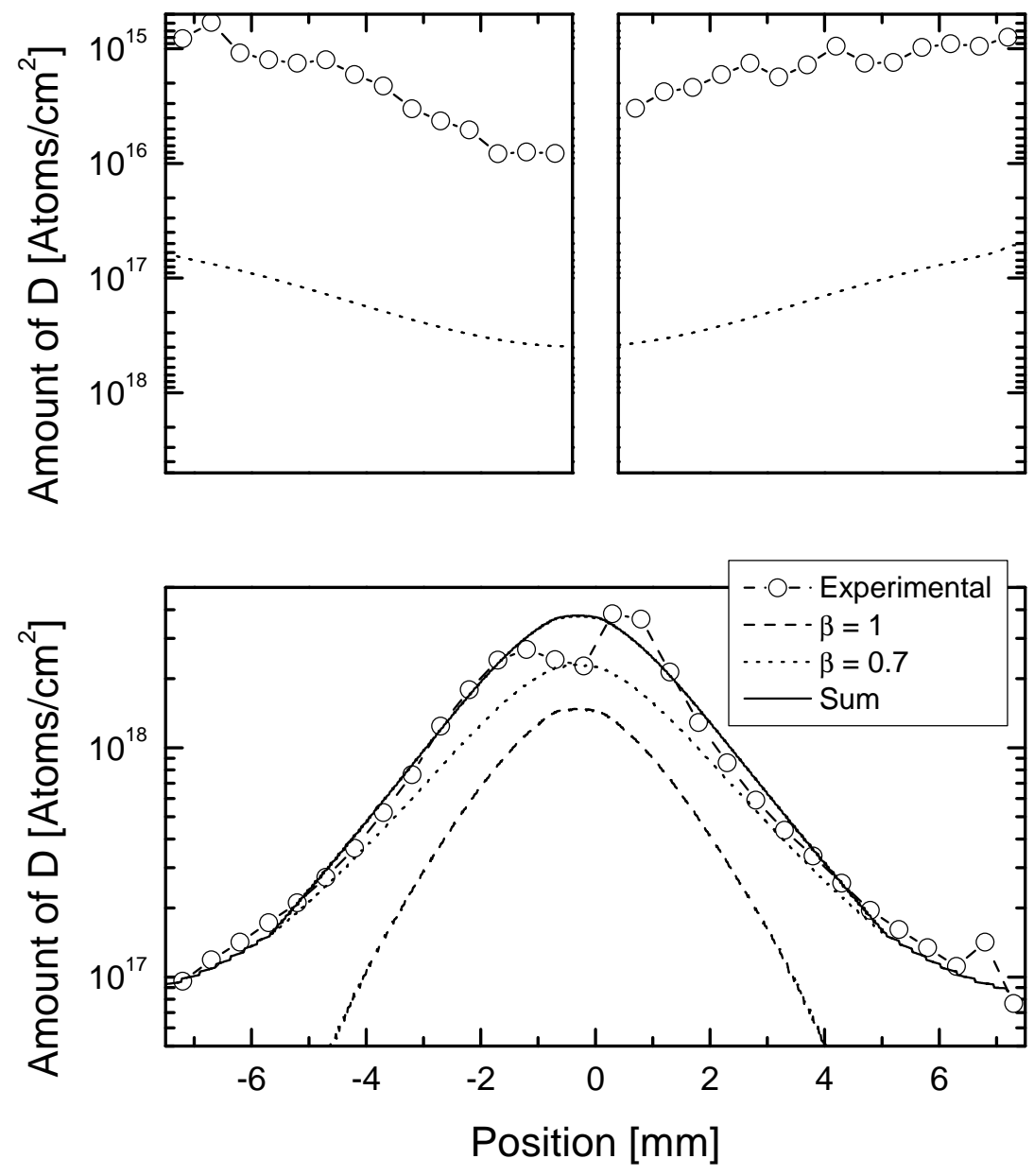

Figure 5. Deuterium distribution inside cavity C 3. Top: top plates; bottom: bottom plate. Note the inverted vertical scale for the deposit on the top plates reflecting their downward growth. Lines: Computer simulations of the deposition pattern using surface loss probabilities of $\beta=0.7, \beta=1.0$, and the sum of both.

\subsection{Heated long term samples}

The amounts of deposited $\mathrm{C}$ and $\mathrm{D}$ on the long term samples as function of sample temperature are shown in Figure 6. In order to monitor toroidal asymmetries, three room temperature samples were exposed in addition to the heated samples. The room temperature samples were placed close to the heated samples. The deposition on one of the three room-temperature samples deviates from the other two due to toroidal variations. However, this variation is much smaller than the effect of sample temperature. The $\mathrm{D} / \mathrm{C}$ ratio of the deposited layers was 0.37 at room temperature and decreased slightly to 0.33 at $200^{\circ} \mathrm{C}$. The amounts of deposited D and $\mathrm{C}$ decrease strongly with sample temperature. The deposition both of $\mathrm{D}$ and $\mathrm{C}$ at $200^{\circ} \mathrm{C}$ is about 70 times smaller than at room temperature. 


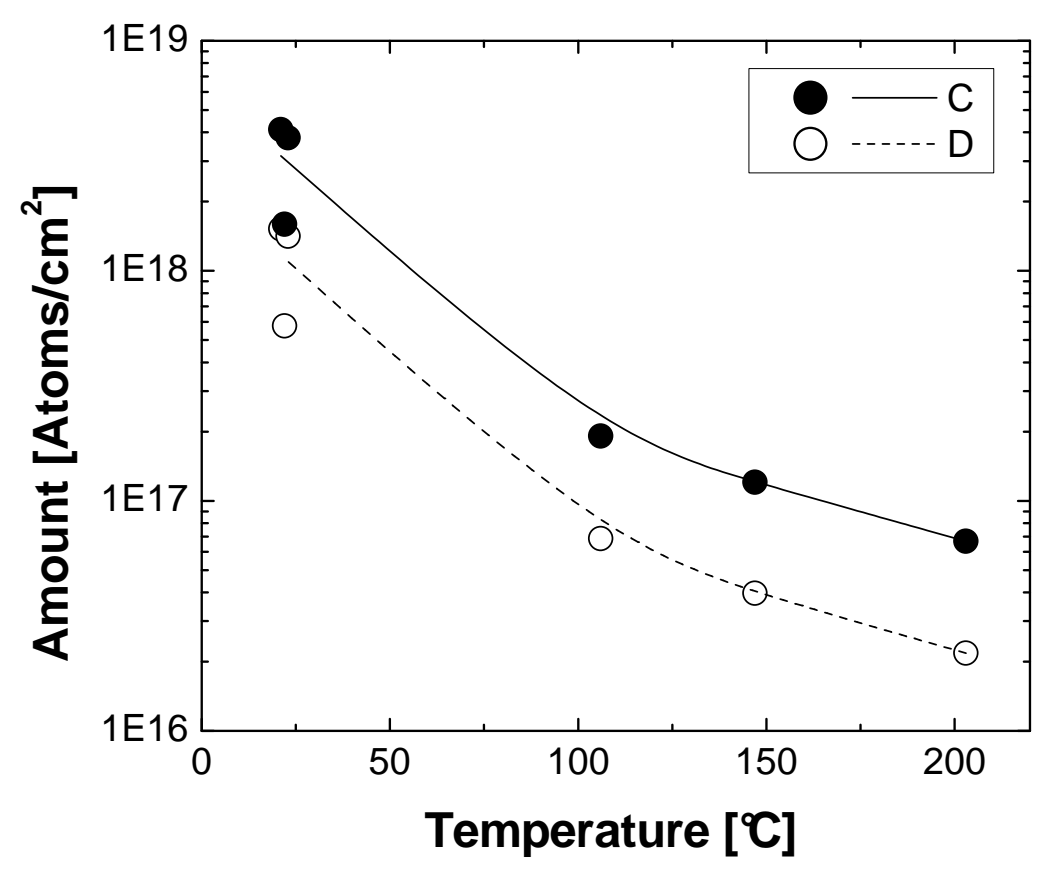

Figure 6. Amounts of deposited $\mathrm{C}$ and $\mathrm{D}$ on the long term samples as function of sample temperature. The room temperature data points have been shifted to the left and right for better visibility. Lines to guide the eye.

\section{Discussion}

To describe the deposition pattern of $\mathrm{D}$ and $\mathrm{C}$ inside the cavities requires at least two different hydrocarbon radical species, see subsection 4.1 for details.

(i) One species has a surface loss probability $\beta$ close to unity. This species may be $\mathrm{C}_{2} \mathrm{D}$ radicals, which have $\beta=0.9 \pm 0.05$ [12]. Stable $\mathrm{C}_{2} \mathrm{D}_{x}$ molecules (with $x=2,4,6$ ) are observed in residual gas mass spectra after plasma discharges, so that the formation of $\mathrm{C}_{2} \mathrm{D}_{y}$ radicals (with $y=1,3,5$ ) is probable. Other possible candidates are $\mathrm{CD}_{z}$ $(z=1,2)$ and $\mathrm{C}_{3} \mathrm{D}_{m}$ radicals, for which the sticking probabilities are not known, but may be high. Carbon atoms or small carbon cluster are other possible candidates - deuterium may be further incorporated by chemical reactions with deuterium atoms.

However, this assignment between surface loss probability and radical species is not unambiguous, because the surface loss probability of hydrocarbon molecules approaches unity at energies above about $2 \mathrm{eV}$ according to molecular dynamics calculations $[20,21]$. The observed high surface loss probability therefore might be due to energetic hydrocarbon molecules.

(ii) A second species with $\beta$ in the range $0.2-0.3$. This may be $\mathrm{C}_{2} \mathrm{D}_{x>2}$, which have $\beta=0.35 \pm 0.1[12]$.

(iii) Due to the small size of the cavities, this technique is not sensitive to particles with 
$\beta \ll 0.1$, if higher sticking particles are present. It is well known, that $\mathrm{CD}_{3}$ radicals have a very low surface loss probability $\beta \ll 0.01$ - the precise value depends on the atomic hydrogen flux [12, 22, 23]. As $\mathrm{CD}_{4}$ is the most prominent stable hydrocarbon molecule in residual gas mass spectra after plasma discharges, it is expected that significant amounts of $\mathrm{CD}_{3}$ radicals are formed. Indeed, a radical with $\beta<10^{-3}$ was observed to form hydrocarbon layers in the pump ducts of ASDEX Upgrade [11], which is most probably $\mathrm{CD}_{3}$. Because the pump ducts can be reached by particles from the plasma only after several wall collisions, measurements in the ducts are much more sensitive to low sticking species.

These results from ASDEX Upgrade are in qualitative agreement with measurements using cavity samples in the JET divertor, where three different species with $\beta \approx 1, \beta=0.9$ and $\beta=10^{-3}$ were observed [8]. The $\beta=0.2-0.3$ species is observed at ASDEX Upgrade, but not at JET, while the $\beta=0.9$ seems to exist at JET, but not at ASDEX Upgrade. However, if in addition re-erosion of already deposited layers plays a role, results from the cavity technique become difficult to interpret, and the derived surface loss probabilities may be inaccurate by a factor of about two to three. A spatial variation of the sticking coefficient due to activation of the surface within the cavity (for example by energetic particles, soft X-rays etc.) may result in additional errors. Under these conditions the $\beta=0.9$ and $\beta=0.2-0.3$ species actually may be identical. Keeping these inaccuracies in mind, we can conclude that three species are observed at ASDEX Upgrade and JET: One high sticking species with $\beta=1$, one with $\beta$ in the range $0.2-0.9$, and another with $\beta \approx 10^{-3}$. As already mentioned above, the observed high sticking might be due to energetic hydrocarbon molecules with energies of a few eV.

Sticking of carbon atoms and hydrocarbon radicals is only one process governing the formation of hydrocarbon layers. The experimental findings with the cavities cannot be explained by sticking alone. The much too small hydrocarbon layer deposition on both sides of the top plates of cavities C 1 and C 3 (Table 1 and Figure 5) requires an additional mechanism as explanation. As was shown with the heated long term samples, layer deposition decreases strongly with temperature. Due to the bad thermal conductivity of the Si wafers used for the top plates, they can be heated by radiation from the plasma, thus resulting in smaller deposition. This effect is more pronounced for cavities $\mathrm{C} 1$ and $\mathrm{C} 3$, which face the divertor plasma, and does not play a role for cavities $\mathrm{C} 2$ and $\mathrm{C} 4$, which are more recessed or oriented away from the plasma. The same effect was already observed with cavity samples in a low temperature plasma laboratory experiment, and was also explained as a temperature effect [14]. Erosion of already deposited layers was also observed below the ASDEX Upgrade roof baffle under some plasma conditions with quartz micro balances [30].

What is the reason for the strong temperature dependence of the hydrocarbon layer growth rate (see Figure 6)? A possible explanation would be a strong temperature dependence of the sticking coefficient. However, it is difficult to imagine from molecular physics how the sticking coefficient can change by about two orders of magnitude within 
a temperature interval of only $200 \mathrm{~K}$, so that this explanation seems unlikely.

It was already observed in laboratory experiments, that the chemical erosion yield of hydrocarbon layers bombarded by thermal atomic hydrogen atoms increases strongly with temperature from room temperature to $500 \mathrm{~K}$ [24, 25]. Erosion of a-C:D layers by atomic hydrogen was also observed at the plasma generator PSI-2 [26]. It was concluded from these experiments, that during simultaneous bombardment with atomic hydrogen and hydrocarbon radicals the flux of atomic hydrogen determines whether net deposition or net erosion is observed [25, 27]. Consequently, we attribute the observed temperature dependence of the hydrocarbon layer growth rate to a temperature dependence of the re-erosion of already deposited layers by thermal (or low-energetic) hydrogen atoms. Hydrogen atoms are abundant in the divertor plasma. The recombination coefficient of hydrogen atoms on clean stainless steel surfaces is about 0.1 [28], about $10^{-4}$ on insulators like glass [29], and 0.01-0.02 on hydrogen saturated carbon [14], such as the amorphous hydrocarbon layers which cover all areas in vicinity of the divertor. Hydrogen atoms are therefore able to survive about 100 wall collisions due to the low recombination coefficient, and can leak out easily from the divertor region. A parasitic plasma was observed below the roof baffle [30], which acts as additional hydrogen atom source. The observed decrease of the layer thickness even in the inner top corners of the cavities can be explained only by the action of thermal particles, which are able to survive at least dozens of wall collisions.

Re-erosion by thermal atomic hydrogen may also explain the very small hydrocarbon layer growth rate in the pump ducts of ASDEX Upgrade [11]: The small growth rate might be interpreted as a small incident flux of low sticking species. However, the most common hydrocarbon radical should be $\mathrm{CD}_{3}$, which has a low sticking probability. Therefore, the flux of low sticking species and consequently the a-C:D layer formation in remote areas should be much larger than observed. But already a small re-erosion yield by atomic hydrogen of the order of $10^{-5}$ at room temperature would be sufficient to effectively suppress hydrocarbon layer formation in remote areas.

\section{Conclusions}

As was shown experimentally with cavity samples and heated long term samples below the roof baffle of ASDEX Upgrade, the growth of hydrocarbon layers in remote areas of nuclear fusion devices is determined by two competing processes: Layer growth by sticking of hydrocarbon radicals, and re-erosion of already deposited layers by thermal hydrogen atoms. The re-erosion is strongly temperature dependent. Whether net deposition or net erosion dominates at a specific position, depends on the flux ratio and the sample temperature. This is in good agreement with laboratory low temperature plasma experiments [25, 27].

At least three different surface loss probabilities $\beta$ are observed: a surface loss probability close to unity, a second $\beta$ between 0.2 and 0.9 , and a third $\beta<10^{-3}$. These different surface loss probabilities may be due to different radical species, but may be 
also due to thermal and energetic hydrocarbon molecules. The contribution of each species to the hydrocarbon layer growth depends on the location: On areas with line-ofsight to the divertor strike point the high sticking species play a dominant role and are responsible for more than $2 / 3$ of the deposition. In areas without direct line-of-sight, which are only accessible after several wall collisions, layer formation by low sticking species becomes important.

The competition between these processes makes computer simulations and predictions of hydrocarbon layer growth rates difficult. The transport of hydrocarbon radicals can by modelled by Monte-Carlo methods even in complicated geometries like the ITER pump ducts [31]. Identical methods can be used for calculating the transport of hydrogen atoms, provided that the recombination coefficients are known. The net effect is given by the difference in the two simultaneous processes of sticking and reerosion. Already small inaccuracies in the sticking and recombination coefficients, reerosion yields, and incident fluxes of hydrocarbon radicals and hydrogen atoms influence the net result strongly. At the moment both sticking coefficients and re-erosion yields are known only with large inaccuracies. Measurements of hydrocarbon radical and atomic hydrogen fluxes in remote areas (such as the sub-divertor area in ASDEXUpgrade or the louver area in JET) are not available. As a consequence, computer simulations of hydrocarbon layer growth rates and predictions of tritium inventories of future machines are subject to large uncertainties. Without accurate measurements of sticking coefficients, re-erosion yields, and fluxes of atomic hydrogen and hydrocarbon radicals in the divertor, this situation will not improve in the near future.

The temperature dependence of the re-erosion yield may offer a possibility to suppress hydrocarbon layer deposition on diagnostic mirrors in the divertor. On hot mirror surfaces the re-erosion yield by atomic hydrogen is enhanced, and hydrocarbon layer growth may be retarded or even completely suppressed. Although our data are for silicon substrates, and ITER diagnostic mirrors are foreseen to be made from molybdenum, the different material affects only the initial stage of layer growth: Once the deposited layer has reached a thickness of a few monolayers, the underlying substrate is no longer important due to the low particle energies.

Beryllium will be eroded at the ITER main chamber walls and transported to the divertor, where it will be redeposited. Beryllium layers on diagnostic mirror surfaces are not eroded by thermal hydrogen atoms, and may be very difficult to remove.

Hydrocarbon layer growth on liquid nitrogen cooled cold surfaces is larger by a factor of at least 40 than at room temperature. This may be important for the tritium inventory on liquid nitrogen cooled cryo shields in ITER. Such cold surfaces may also offer a possibility to catch hydrocarbon radicals or molecules at well defined areas.

\section{Acknowledgments}

Helpful discussions with W. Jacob from IPP Garching are gratefully acknowledged. 


\section{References}

[1] MAYER, M., PHILIPPS, V., WIENHOLD, P., ESSER, H., VON SEGGERN, J., et al., J. Nucl. Mater. 290-293 (2001) 381. 1

[2] FEDERICI, G., ANDERL, R., ANDREW, P., BROOKS, J., CAUSEY, R., et al., J. Nucl. Mater. 266-269 (1998) 14. 1

[3] FEDERICI, G., BROOKS, J., COSTER, D., JANESCHITZ, G., KUKUSKHIN, A., et al., J. Nucl. Mater. 290-293 (2001) 260. 1

[4] FEDERICI, G., ANDREW, P., BARABASCHI, P., BROOKS, J., DOERNER, R., et al., J. Nucl. Mater. 313-316 (2003) 11. 1

[5] COAD, J., BEKRIS, N., ELDER, J., ERENTS, S., HOLE, D., et al., J. Nucl. Mater. 290-293 (2001) 224. 1

[6] COAD, J., ANDREW, P., HOLE, D., LEHTO, S., LIKONEN, J., et al., J. Nucl. Mater. 313-316 (2003) 419. 1

[7] MAYER, M., ROHDE, V., LIKONEN, J., VAINONEN-AHLGREN, E., KRIEGER, K., et al., J. Nucl. Mater. 337-339 (2005) 119. 1

[8] MAYER, M., VON KEUDELl, A., ROHDE, V., COAD, P., and JET-EFDA contributors, Mechanism of hydrocarbon layer formation in remote areas of fusion devices, in 30th EPS Conference on Controlled Fusion and Plasma Physics, volume 27A of europhysics conference abstracts, pages O-2.6A, 2003. 1, 2, 12

[9] ROHDE, V., MAIER, H., KRIEGER, K., NEU, R., PERCHERMAIER, J., et al., J. Nucl. Mater. 290-293 (2001) 317. 1

[10] ROHDE, V., MAYER, M., and ASDEX Upgrade Team, Physica Scripta T103 (2003) 25. 1

[11] MAYER, M., ROHDE, V., VON KEUDELL, A., and the ASDEX Upgrade Team, J. Nucl. Mater. 313-316 (2003) 429. 1, 2, 5, 12, 13

[12] VON KEUDELL, A., HOPF, C., SCHWARZ-SELINGER, T., and JACOB, W., Nucl. Fusion 39 (1999) 1451. 1, 2, 4, 5, 11, 12

[13] JACOB, W., HOPF, C., VON KEUDELL, A., and SCHWARZ-SELINGER, T., Surface loss probabilities of hydrocarbon radicals on amorphous hydrogenated carbon film surfaces: Consequences for the formation of re-deposited layers in fusion experiments, in Hydrogen Recycling at Plasma Facing Materials, edited by WU, C.-H., volume II/1 of NATO Science Series, pages 331-337, Kluwer Academic Publishers, P.O.Box 322, 3300 AH Dordrecht, The Netherlands, 2000. 1

[14] VON KEUDELL, A., SCHWARZ-SELINGER, T., JACOB, W., and STEVENS, A., J. Nucl. Mater. 290-293 (2001) 231. 1, 12, 13

[15] VOITSENYA, V., BARDAMID, A., BONDARENKO, V., JACOB, W., KONOVALOV, V., et al., J. Nucl. Mater. 290-293 (2001) 336. 1, 2

[16] ALIMOV, V. K., MAYER, M., and ROTH, J., Nucl. Instr. Meth. B234 (2005) 169. 4

[17] MAYER, M., SIMNRA user's guide, Technical Report IPP 9/113, Max-Planck-Institut für Plasmaphysik, Garching, 1997. 4

[18] MAYER, M., SIMNRA, a simulation program for the analysis of NRA, RBS and ERDA, in Proceedings of the 15th International Conference on the Application of Accelerators in Research and Industry, edited by DUGGAN, J. L. and MORGAN, I., volume 475 of AIP Conference Proceedings, page 541, American Institute of Physics, 1999. 4

[19] ROTH, J. and HOPF, C., J. Nucl. Mater. 334 (2004) 97.8

[20] ALMAN, D. and RUZIC, D., J. Nucl. Mater. 313-316 (2003) 182. 11

[21] SHARMA, A., SCHNEIDER, R., VON TOUSSAINT, U., and NORDLUND, K., Hydrocarbon radicals interaction with amorphous carbon surfaces, presented at the 17th International Conference on Plasma Surface Interactions in Controlled Fusion Devices, Hefei, China, 2006, submitted to J. Nucl. Mater. 11

[22] VON KEUDELL, A., SCHWARZ-SELINGER, T., and JACOB, W., J. Appl. Phys. 89 (2001) 
2979. 12

[23] VON KEUDELL, A. and JACOB, W., Progr. Surf. Sci. 76 (2004) 21. 12

[24] VIETZKE, E. and PHILIPPS, V., Nucl. Instr. Meth. B23 (1987) 449. 13

[25] VON KEUDELL, A. and JACOB, W., J. Appl. Phys. 79 (1996) 1092. 13

[26] NAUJOKS, D., BOHMEYER, W., MARKIN, A., ARKHIPOV, I., CARL, P., et al., Physica Scripta T111 (2004) 80. 13

[27] JACOB, W., J. Nucl. Mater. 337-339 (2005) 839. 13

[28] MOZETIČ, M., DROBNiČ, M., and ZALAR, A., Appl. Surf. Sci. 144-145 (1999) 399. 13

[29] WOOD, B., MILlS, J., and WISE, H., J. Phys. Chem. 67 (1963) 1462. 13

[30] ROHDE, V., MAYER, M., NEUHAUSER, J., and ASDEX Upgrade Team, J. Nucl. Mater. 313316 (2003) 337. 12, 13

[31] Federici, G., MAYer, M., Strohmayer, G., ChuYAnOV, V., , et al., J. Nucl. Mater. 337 - 339 (2005) 40.14 